\title{
Biliary duct-to-duct anastomosis using magnets in a Billroth II gastrectomy patient
}

The usefulness of magnetic compression anastomosis (MCA) for biliary duct-toduct anastomosis had been reported in patients with normal anatomy or after liver transplantation [1-4]. Here we report a case of successful MCA for biliary ductto-duct anastomosis, carried out in a 65year-old woman who underwent Billroth II gastrectomy for pyloric stenosis at the age of 17 years. Regarding the patient's present condition, 2 years after liver central bisegmentectomy (with common bile duct preservation) for hepatoma, she developed hilar biliary obstruction. To treat this, we carried out posterior segmental branch percutaneous transhepatic biliary drainage (PTBD). As the patient refused re-operation, we carried out MCA. As described previously [1-3], we initially placed a 16-Fr PTBD tube to dilate the biliary tract, after which two 7-Fr plastic stents were placed up to the right hepatic bile duct using a colonoscope. Magnetic retrograde cholangiopancreatography (MRCP) and computed tomography $(\mathrm{CT})$ revealed that the distance between the PTBD tube and the endoscopic biliary drainage tube was approximately $15 \mathrm{~mm}$ ( $\bullet$ Fig. 1). At 2 weeks after stent placement, we carried out MCA. A samarium cobalt rare-earth magnet was advanced in front of the papilla with a biopsy forceps using an oblique-viewing endoscope (XK240, Olympus, Tokyo, Japan). The magnet was then inserted up to the right hepatic duct under fluoroscopic guidance. Another magnet was advanced to the right hepatic duct via the PTBD route, and the two magnets were attracted towards each other ( $\bullet$ Fig. 2 a). The following day, the magnets were observed to be almost in total contact with each other ( Fig. 2b). After 1 month, the two approximating magnets were removed via the PTBD route and a 14-Fr internal fistula tube was placed ( Fig.3). To the best of our knowledge, this is the first report on successful MCA in a Billroth II gastrectomy patient. MCA may be beneficial for biliary duct-to-duct anastomosis in selected pa-

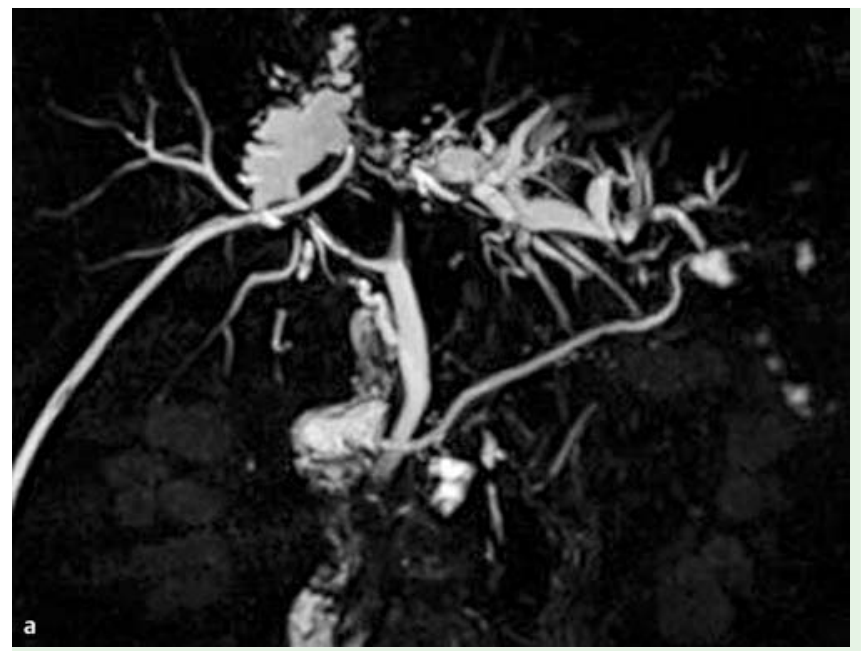

Fig. 1 a Magnetic resonance cholangiopancreatography (MRCP) showing biliary obstruction between the posterior segmental branch of the bile duct and the common bile duct. $\mathbf{b}$ The distance between the percutaneous transhepatic biliary drainage tube and the endoscopic biliary drainage tube was confirmed to be $15 \mathrm{~mm}$ by abdominal computed tomography (CT).

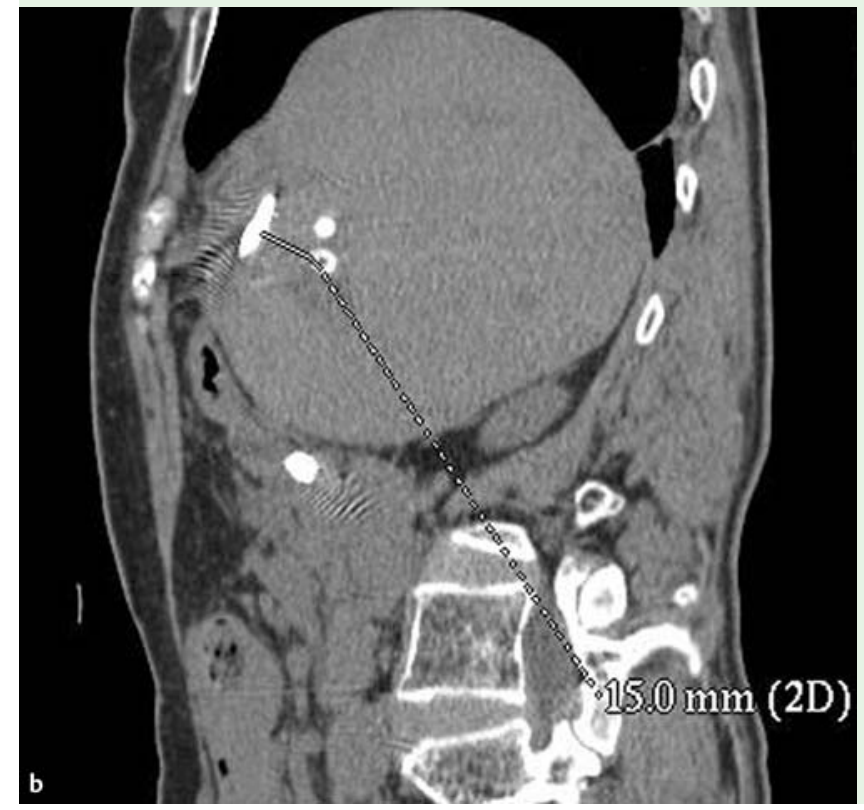

\section{T. Tsuchiya ${ }^{1}$, T. Itoi ${ }^{1}$, A. Sofuni ${ }^{1}$, F. Itokawa', D. K. Lee ${ }^{2}$}

${ }^{1}$ Department of Gastroenterology and Hepatology, Tokyo Medical University Hospital, Shinjuku-ku, Tokyo, Japan

2 Department of Internal Medicine, Gangnam Severance Hospital, Yonsei University College of Medicine, Seoul, Republic of Korea

\section{Acknowledgments} $\nabla$

We thank Dr Clifford Kolba, Associate Professor Edward Barroga, and Professor J. Patrick Barron, Chairman of the Department of International Medical Communications of Tokyo Medical University for their editorial review of this article.

Endoscopy_UCTN_Code_TTT_1AR_2AG

Competing interests: None 

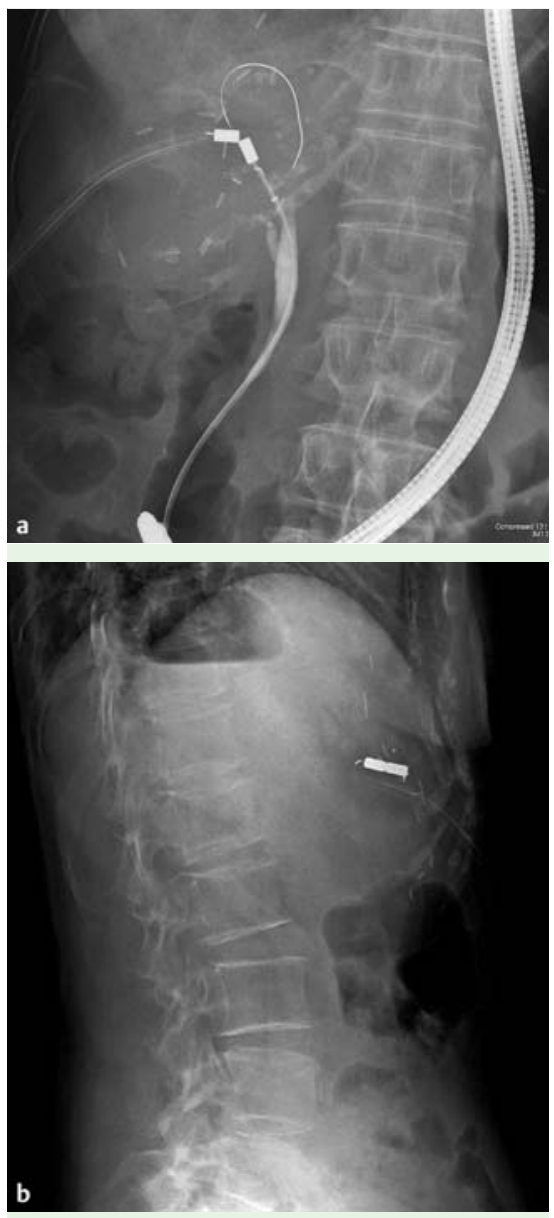

Fig. 2 a The first magnet was inserted up to the right hepatic duct under fluoroscopic guidance through the papilla. The second magnet was inserted via the percutaneous transhepatic biliary drainage route and placed at a site where it appeared to move toward the first magnet. b The following day, the magnets were in almost total contact with each other.

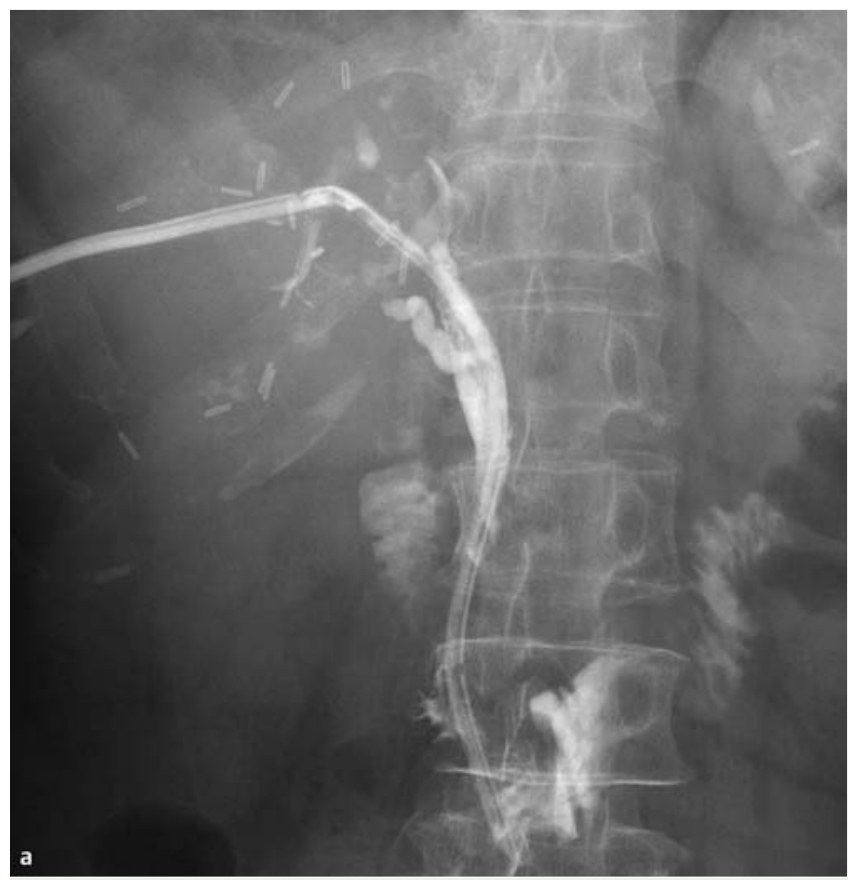

Fig. 3 a The two magnets were removed via the percutaneous transhepatic biliary drainage route, and a 14-Fr internal fistula tube was placed. b Necrotic tissue was found between the magnets after removal.

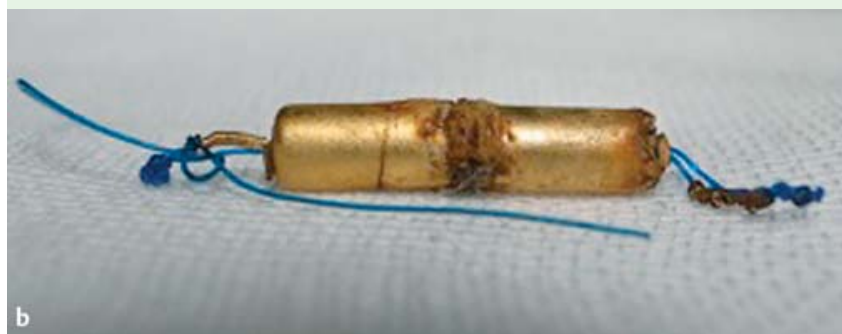

\section{References}

1 Itoi $T$, Kasuya K, Sofuni $A$ et al. Magnetic compression anastomosis for biliary obstruction: review and experience at Tokyo Medical University Hospital. J Hepatobiliary Pancreat Sci 2011; 18: 357-365

2 Itoi T, Yamanouchi E, Ikeuchi $N$ et al. Magnetic compression duct-to-duct anastomosis for biliary obstruction in a patient with living donor liver transplantation. Gut Liver 2010; 4: 96-98

3 Itoi T, Yamanouchi E, Ikeda T et al. Magnetic compression anastomosis: a novel technique for canalization of severe hilar bile duct strictures. Endoscopy 2005; 37: $1248-1251$

4 Jang SI, Kim JH, Won JY et al. Magnetic compression anastomosis is useful in biliary anastomotic strictures after living donor liver transplantation. Gastrointest Endosc 2011; 74: 1040-1048

\section{Bibliography}

Dol http://dx.doi.org/

10.1055/s-0032-1310071

Endoscopy 2013; 45: E243-E244

(c) Georg Thieme Verlag KG

Stuttgart · New York

ISSN 0013-726X

\section{Corresponding author}

\section{T. Tsuchiya}

Department of Gastroenterology and Hepatology

Tokyo Medical University Hospital

6-7-1 Nishishinjuku

Shinjuku-ku

Tokyo 160-0023

Japan

Fax: +81-3-53816654

tsuchiya@tokyo-med.ac.jp 